\title{
Fallon fox: um corpo queer no octógono
}

\author{
Carla Lisboa Grespan* \\ Silvana Vilodre Goellner**
}

\begin{abstract}
Resumo: Fundamentado nos estudos de gênero e na teorização queer, este texto analisa a inserção de Fallon Fox como atleta profissional do Mixed Martial Arts, mais especificamente, a luta contra Allanna Jones nas semifinais do Championship Fighting Alliance. Para tanto, analisa 510 comentários postados em três artefatos culturais específicos de lutas, buscando apreender os discursos que seus usuários produziram sobre a participação de uma atleta transgênero. Da análise dos dados empíricos, foi possível identificar que os argumentos utilizados para justificar o caráter impróprio da disputa estavam assentados em duas perspectivas: a utilização de discursos jurídicos e médicos para atestar a vantagem de Fallon Fox sobre sua oponente e a transfobia, entendida como a aversão ou repulsa a pessoas trans.
\end{abstract}

Palavras-chave: Artes Marciais Mistas. Transgênero. Atletas.

\section{INTRODUÇÃo}

Identificado como uma prática esportiva caracterizada pelo emprego de técnicas oriundas de diversas artes marciais e de esportes de combate, o MMA (Mixed Martial Arts ou Artes Marciais Mistas) tem conquistado um espaço privilegiado no universo cultural das lutas, sobretudo a partir de sua ampla divulgação na mídia esportiva, promovida, em grande medida, pelo Ultimate Fighting Championship (UFC), a maior organização de MMA do mundo ${ }^{1}$. Sites, blogs, revistas especializadas, programas de televisão, canais exclusivos, entre outros artefatos midiáticos, são facilmente visualizados no nosso cotidiano, arregimentando um número crescente de produtos e consumidores.

\footnotetext{
*Programa de Pós-graduação em Ciências do Movimento Humano. Escola de Educação Física. Universidade Federal do Rio Grande do Sul (UFRGS). Porto Alegre, RS, Brasil. E-mail: carla.grespan@ufrgs.br

** Programa de Pós-graduação em Ciências do Movimento Humano. Escola de Educação Física. Universidade Federal do Rio Grande do Sul (UFRGS). Porto Alegre, RS, Brasil. E-mail: vilodre@gmail.com ${ }^{1} \mathrm{Em}$ 2013, o UFC promoveu 33 eventos em 27 cidades diferentes, totalizando 65 horas de luta, batendo o recorde de expansão no ano de seu $20^{\circ}$ aniversário. Segundo o site MMA Junkie, o UFC teve um total de público de 407.452 pagantes e uma renda de US $\$ 52,8$ milhões (DEHÓ, 2014).
} 
Em que pese a potente produção midiática em torno do MMA, o ano de 2013 foi palco de um acontecimento ${ }^{2}$ bastante significativo para esse esporte, inclusive com o objetivo de ampliar o rol de consumidores: o Ultimate Fighting Championship (UFC) promoveu sua primeira luta entre mulheres, realizada no dia 23 de fevereiro, em Los Angeles, ocasião em que as americanas Ronda Rousey e Liz Carmouche disputaram o Cinturão do Peso Galo. Esse evento não passou despercebido pelos produtores e consumidores de notícias, gerando opiniões diversas sobre a presença de mulheres em um campo representado como de domínio masculino. Apesar de essa luta não ser propriamente uma novidade nas disputas de MMA, sua oficialização e ampla divulgação contribuiu para que as mulheres tivessem maior visibilidade e reconhecimento nesse esporte. Vale lembrar que no UFC 168, realizado no dia 28 de dezembro de 2013, em Las Vegas, a luta entre Ronda Rousey e Miesha Tate participou do main card (evento principal), antecedendo a revanche de Anderson Silva contra Chris Weidman, sendo inclusive considerada a melhor luta da noite.

Ainda que a oficialização das mulheres tenha demarcado uma importante conquista para as atletas no MMA, o ano de 2013 reservou outra novidade: a luta entre a atleta transexual Fallon Fox e Allanna Jones no dia 24 de março, nas semifinais do Championship Fighting Alliance ${ }^{3}$. Tal acontecimento foi amplamente noticiado em diferentes artefatos midiáticos, desencadeando reações diversas, sobretudo porque colocou em cena um corpo queer. Um corpo que desafia as normas regulatórias, excêntrico, ambíguo; "um corpo estranho, que incomoda, perturba, provoca e fascina" (LOURO, 2004, p. 7-8).

Fundamentado nos estudos de gênero e na teorização queer ${ }^{4}$, este texto analisa questões relativas à inserção de Fallon Fox no

\footnotetext{
${ }^{2}$ Tomamos aqui a noção de acontecimento a partir da proposição de Michel Foucault, que o identifica como a irrupção de uma singularidade histórica (REVEL, 2011).

${ }^{3}$ Organização norte-americana de MMA fundada em 2001, com sede em Miami, EUA.

${ }^{4}$ Sobre a teoria queer e sua apropriação no Brasil, sugere-se a leitura de Guacira Louro (2004), Richard Miskolci (2012) e Sara Salih (2012).
}

Movimento, Porto Alegre, v. 20, n. 4, p. 1265-1282, out./dez. de 2014. 
âmbito das lutas de MMA. Para tanto, examinam-se os comentários postados em dois sites e um blog de lutas, buscando apreender como os usuários dessas redes sociais reagiram à participação de uma atleta transgênero no octógono. Da observação dos dados empíricos, emergiram duas categorias de análise: o discurso ${ }^{5}$ biomédico, o qual é tomado para explicar o funcionamento do corpo humano e assim justificar o caráter impróprio dessa luta, e a transfobia, entendida como a aversão ou discriminação contra pessoas trans (transgêneros, transexuais e travestis).

\section{Diálogos com o octógono: a Rainha de Espadas ${ }^{6}$}

Ao declarar-se transexual, Fallon Fox concedeu algumas entrevistas nas quais narra como Boyd Burton, nascido em 1975 na cidade de Toledo (EUA), tornou-se a Rainha das Espadas. Ressalta que sua família era bastante conservadora e cristã, o que fez com que, aos 17 anos, quando assumiu sua homossexualidade, fosse submetida a uma terapia religiosa de conversão gay. Aos 19, engravidou uma garota, casou e alistou-se na Marinha, com o objetivo de sustentar a família, o que fez, posteriormente, dirigindo caminhões. Insatisfeita com seu corpo desde a infância, Fallon iniciou o processo de ressignificação sexual em 2003, realizando sua primeira cirurgia em 2006 no Hospital Nacional de Bangkok, e a última em 2011, quando "feminizou" a face, corrigindo os ossos da testa, a linha da mandíbula e a calvície. Sua inserção nas lutas se deu em meio a esse processo, e desde 2008 participou de competições de wrestling, jiu-jitsu e muay thai. Em junho de 2011,

\footnotetext{
${ }^{5}$ Utilizamos o conceito de discurso de Michel Foucault, sistemas e códigos de significação que constituem o conjunto de enunciados de um determinado campo de saber, construídos historicamente dentro das relações de poder. Assim o discurso "é o objeto de desejo; [...] aquilo por que, pelo que se luta, o poder do qual nos queremos apoderar" (FOUCAULT, 1996, p. 10).

${ }^{6} \mathrm{~A}$ atleta passou a autodenominar-se desse modo em função de sua identificação com a imagem da Queen of Swords do baralho de tarô. Em entrevista, afirma: "Ela é forte, ela é orgulhosa, ela é inteligente... é assim que eu quero ser. Essa é a pessoa que eu quero me tornar e colocar lá fora. Foi um momento muito emocionante para mim, e eu decidi que iria mantê-lo como meu nome luta". Disponível em: <http://bleacherreport.com/articles/1648786transgender-trailblazer-fallon-fox-talks-jason-collins-x-men-being-a-pioneer> Acesso em: 18 jan. 2014.
}

Movimento, Porto Alegre, v. 20, n. 4, p.1265-1282, out./dez. de 2014. 
estreou no octógono e, em maio de 2012, disputou sua primeira luta profissional, contabilizando três vitórias consecutivas.

A participação oficial de Fallon Fox no MMA desencadeou discussões relacionadas à legitimidade de sua presença nesse esporte. Vários dos argumentos convocados para atestar a arbitrariedade do acontecimento tinham como fundamentação o discurso biológico e o saber médico que, ao enfatizarem a transexualidade da atleta, colocavam como questão a pertinência de que um homem biológico, anatomicamente transformado em uma mulher, pudesse lutar contra outras mulheres. Em resposta a essa polêmica, Hellen Carrol, ex-atleta e advogada de atletas transexuais, argumenta que a mulher transexual é uma mulher que, no processo de ressignificação, ingere bloqueio de hormônios (testosterona), ou seja, ela tem menos testosterona em seu organismo do que as suas concorrentes, demandando maior treinamento para manter a massa muscular e a força do que uma atleta mulher nascida fêmea. Indica ainda que a profusão de estrógenos em seu corpo dificulta a velocidade e a capacidade de reduzir o peso corporal (HUNT, 2013). Enfim, menciona as desvantagens existentes nesse corpo tecnicamente transformado em contraposição a vários argumentos que explicitam que o fato de Fallon ter nascido homem lhe daria mais força física, apesar da transgenerização.

Além das discussões de ordem biológica, o corpo queer de Fallon Fox, ao romper com a linearidade entre sexo, gênero e sexualidade $^{7}$, possibilitou a visibilidade de outros contornos à representação dominante de feminilidade, o que, por sua vez, contribuiu para revelar a potência do discurso heteronormativo ${ }^{8}$ no campo esportivo e fora dele.

\footnotetext{
${ }^{7}$ No início do século XIX, "os corpos entendidos como normais pela medicina passam a ser então o masculino e o feminino, diferentes e complementares. A ciência e, especialmente, a medicina, trabalham arduamente no sentido de atribuir uma série de características/atributos emocionais e comportamentais distintos para cada sexo. Essa imposição de comportamentos sobre uma base biológica acaba sugerindo uma linearidade sexo-gênero-sexualidade, onde o homem-masculino se relaciona somente com a mulher-feminina, dado que ambos são opostos e complementares" (SILVESTRIN, 2013, p. 7).

${ }^{8}$ Heteronormatividade é aqui entendida como "a ordem sexual do presente, fundada no modelo heterossexual, familiar e reprodutivo. Ela se impõe por meio de violências simbólicas e físicas dirigidas principalmente a quem rompe normas de gênero" (MISKOLCI, 2012, p. 44).
}

Movimento, Porto Alegre, v. 20, n. 4, p. 1265-1282, out./dez. de 2014. 


\section{Os CAMINHOS INVESTIGATIVOS}

Uma das formas utilizadas pelos organizadores do MMA para ampliar o público praticante e consumidor de seus eventos e produtos recai em artefatos midiáticos que permitem emitir e receber informações em tempo real, bem como interagir com eles, tais como os blogs, os sites e os canais de transmissão de lutas.

Considerando essa interatividade, optamos por analisar como os usuários de sites esportivos se referiram à inserção de uma atleta transexual no octógono. Para escolher os artefatos que constituíram nosso campo empírico, utilizamos como critério ter ligação com a transmissão exclusiva em TV por assinatura das lutas do UFC e com revistas reconhecidas no campo de esportes de combate. Feito esse filtro, elegemos os sites Combate e Tatame e o blog Na Grade do $M M A^{9}$, cujo foco recaiu exclusivamente nas notícias e nos comentários publicados sobre a luta entre Fallon Fox e Allanna Jones na fase semifinal do Championship Fighting Alliance (CFA). Como recorte temporal, adotamos o período compreendido entre 6 de março (um dia após a atleta declarar-se transexual) ${ }^{10}$ e 25 de maio (um dia após ter vencido a luta). Nos sites analisados, encontramos 15 matérias sobre a luta, sete delas publicadas no site Combate, sete no site Tatame e uma no blog Na Grade do MMA totalizando, em conjunto, 510 comentários de usuários, três deles ultrapassando 100 postagens: "Lutadora transexual considera injusto ter de revelar seu histórico médico" "11; "Transexual enfrenta problemas para obter licença e lutar no MMA feminino"12 e "Apóscríticas à lutadora transexual, Matt Mitrione é suspenso do UFC"13.

${ }^{9}$ Disponiveis respectivamente em: <http://sportv.globo.com/site/eventos/combate>; <http://tatame.com.br>; $<$ <ttp://nagradedomma.blogosfera.uol.com.br>.

${ }^{10}$ Entrevista concedida a Cyd Ziegler. Disponivel em <http://www.outsports.com/2013/3/5/4068840/fallon-foxtrans-pro-mma-fighter>. Acesso em: 28 maio 2013.

${ }_{11}^{11}$ Disponíveis em: <http://sportv.globo.com/site/combate/noticia/2013/03/lutadora-transexual-considera-injustoter-de-revelar-seu-historico-medico.html>. Acesso em: 20 mar. 2013.

${ }_{12}^{12}$ Disponíveis em <http://sportv.globo.com/site/combate/noticia/2013/03/transexual-enfrenta-problemas-paraobter-licenca-e-lutar-no-mma-feminino.html>. Acesso em: 7 fev. 2014.

${ }^{13}$ Disponiveis em: <http://sportv.globo.com/site/combate/noticia/2013/04/apos-criticas-fallon-fox-lutador-mattmitrione-e-suspenso-do-ufc.html>. Acesso em: 9 fev. 2014.

Movimento, Porto Alegre, v. 20, n. 4, p.1265-1282, out./dez. de 2014. 
Visando a uma descrição minuciosa do conteúdo das mensagens postadas, utilizamos como ferramenta analítica a análise de conteúdo (BARDIN, 2011). Para tanto, selecionamos todas as 510 postagens e as examinamos primeiramente em separado e, depois, relacionando-as entre si, buscando apreender os principais temas que colocavam em circulação, assim como os modos como os usuários reagiam a esse acontecimento. Todas as postagens foram catalogadas preservando a identidade de quem as produziu, tanto quanto a sua grafia. Interessa registrar que, dos 510 comentários postados nos três artefatos analisados, 483 foram assinados por homens e 27 por mulheres, o que colabora para visualizar o quanto o esporte e - neste caso específico - o MMA são majoritariamente vivenciados por homens.

Tendo como pano de fundo a polêmica em torno da pertinência (ou não) de um homem que fez a cirurgia de ressignificação sexual lutar contra uma mulher no MMA, dois temas foram recorrentes no material analisado: o discurso médico para justificar as diferenças entre a transexual e a mulher 'natural' e críticas de cunho transfóbico e homofóbico.

\section{4 “Quem A lutadora é (?) Só EXAMES E MÉdicos PODEM AFIRMAR"14}

No dia 6 de março de 2013, o site Combate postou a seguinte reportagem: "Transexual enfrenta problemas para obter licença e lutar no MMA feminino - Fallon Fox, de 37 anos de idade, já tem duas vitórias profissionais, mas pode não ter a licença confirmada após assumir ter mudado de sexo em 2006"15. A matéria teve 104 comentários, quase todos recorrendo ao discurso biomédico para justificar o caráter injusto da luta, visto que o corpo de Fallon era portador de vantagens dadas a priori. Dentre essas destacamos a de Felix Abreu:

\footnotetext{
${ }^{14}$ Expressão retirada do comentário postado por Felix Abreu no site Combate no dia 6 fev. 2013.

${ }^{15}$ Disponível em: <http://sportv.globo.com/site/combate/noticia/ 2013/03/transexual-enfrentaproblemas-para-obter-licenca-e-lutar-no-mma-feminino.html>. Acesso em: 7 fev. 2014.
}

Movimento, Porto Alegre, v. 20, n. 4, p. 1265-1282, out./dez. de 2014. 
Para ser justo tem que se esquecer o fenótipo (aparência) e se analizar o genótipo (carga genética). Se a estrutura corporal e os hormônios são femininos é justo que se enfrente mulheres mas se não for assim é desigual e injusto para com as mulheres. Resumindo, a aparência não dita o sexo, mas a opção sexual, já o sexo é dado pela carga genética do indivíduo e nisso só existe masculino e feminino. Quem a lutadora é só exames e médicos podem afirmar. (TRANSSEXUAL..., 2013(sic)

O modelo binário que figura como pano de fundo da mensagem tem sido amplamente aceito desde meados do século XVIII e pressupõe a existência de dois sexos distintos, os quais originam verdades sobre ser homem e ser mulher, fixando representações de masculinidade e feminilidade ${ }^{16}$. Esse modelo foi recrutado por vários usuários que entendiam ser imprópria a luta entre as duas atletas, como exemplos Loudre, Johnny Be Gude, Fábio e Mérick

Absurdo, mesmo com toda aparencia ela

é HOMEM !! Enquanto nao criarem uma categoria para Trans, ela nao pode lutar contra MULHERES!!!! Biologico vai fazer muita diferença !!! (TRANSSEXUAL, 2013 (sic)

Mitrione apenas deixou claro o que todos já sabem: que o transexual tem a complexão física de homem. E isso não é levado em conta, não é justo. Só mesmo a turminha gay para contestar algo tão óbvio e científico... (CORREA, 2013 (sic)

Concordo total com a punição! Faltou respeito e muito!!! Mas outra coisa é a transsexual lutar contra mulheres, não tenho formação médica, mas me parece desvantagem lutar contra um oponente que tem uma constituição física superior! Não sou nem um pouco machista, apenas realista, se homens e mulheres se equivalecem fisicamente

\footnotetext{
${ }^{16}$ Thomas Laqueur (2001), no livro Inventando o sexo: corpo e gênero dos gregos a Freud, vai tornar evidente como em diferentes momentos históricos o corpo biológico foi tomado como justificador de diferenciações políticas, culturais e sociais entre os sexos.
}

Movimento, Porto Alegre, v. 20, n. 4, p.1265-1282, out./dez. de 2014. 
não teria diferenças tão grandes nos recordes dos esportes. (APÓS..., 2013(sic)

Injusto acho que mesmo fazendo a cirurugia o cara não deixa de ser geneticamente homem e ainda vai ter força de homem. (RONDA..., 2013(sic)

As mensagens acima demarcam o quanto o esporte éum terreno generificado (marcado pela diferença de gênero) e generificador (produz a diferença de gênero), característica que é reforçada em função da forma com a qual é amplamente vivenciado e valorizado e que está profundamente marcado pela divisão binária homem/ mulher. Segundo Ferretti e Knijnik (2007, p. 58):

[...] ele é um dos palcos nos quais se desenrola uma grande parte das definições sobre o que é ser homem ou ser mulher - isto é, o esporte é uma das instituições sociais em que, inclusive por sua corporeidade, se manifestam as ideologias sobre o masculino e o feminino que estão em permanente tensão [...] favorecendo desta forma o emprego das diferenças biológicas para justificar como natural a construção social dos gêneros.

A ordem discursiva que sustenta a harmonização entre corpo, sexo e gênero (vagina/mulher/feminina em oposição a pênis/ homem/masculino) constitui um ato performativo que invisibiliza a existência de outros matizes, inclusive porque sua existência coloca em suspeição a força de tal linearidade.

Aquellos cuerpos cuyo género no es una consecuencia de su sexo anatómico, aquellos cuerpos cuyas prácticas y deseos sexuales no se corresponden con el deseo heterosexual, e incluso aquellos cuerpos que no poseen una definición clara de su condición anatómica (como es el caso de los intersexuales) caen fuera de la matriz de inteligibilidad, siendo, por lo tanto, ininteligibles o incomprensibles. Estos cuerpos serán, por ello, rechazados, marginados, excluidos y, en ocasiones, patologizados. (MELONI, 2008, p. 77).

Movimento, Porto Alegre, v. 20, n. 4, p. 1265-1282, out./dez. de 2014. 
O corpo de Fallon Fox, ao desarmonizar a ordem binária dos sexos e desconstruir representações historicamente produzidas cujos efeitos normalizam ${ }^{17}$ os corpos, seus gêneros e suas sexualidades, coloca em tensão aquilo que o saber médico nomeia como normal. Por essa razão, é considerado inadequado para o espaço ao qual reivindica pertencimento, qual seja, do universo das lutas, no qual os atributos socialmente considerados masculinos são vivenciados com potência e rigor. As falas dos usuários Vanderlei Silva, Jacques Henrique, Leandro Vianna e Fernando Ferz expressam esse tensionamento:

Mano olha a noticia isso da é um homem, isso devo tomar vergonha na cara arrumar uma namorada um emprego e seguir na vida, po o cara tem bolas tem pelo tem gogó e quer lutar com uma mulher, po por baixo o homem tem $60 \%$ mais de força bruta que a mulher, tem umas noticia que da nojo. (TRANSEXUAL..., 2013(sic)

concordo, homem é homen e mulher é mulher, isso é a natureza! Fora isso é anomalia da natureza. (TRANSEXUAL..., 2013(sic)

Quer dizer então que durante décadas o seu corpo (músculos, nervos etc) se desenvolveu cheio de testosterona, aí, de alguns anos pra cá, você toma carga de progesterona e pronto; seu corpo agora é um corpo de mulher. Não beira o ridículo, porque já passou disso faz tempo. Porém, o pior disso é nenhum comentarista esportivo famoso, médico, desportista ter a coragem de se manifestar diretamente contra essa bobagem, mesmo tendo dentro de si a conciência dessas declarações impropérias. (LUTADORA..., 2013(sic)

Não é porque ela/ele pensa como mulher, que seu corpo e estrutura são de uma mulher!O negócio ta ficando estranhooooo! (RONDA..., 2013(sic)

\footnotetext{
${ }^{17}$ Normalizar significa eleger - arbitrariamente - uma identidade específica com parâmetro em relação ao qual as outras identidades são avaliadas e hierarquizadas. Normalizar significa atribuir a essa identidade todas as características positivas possíveis, em relação às quais as outras identidades só podem ser avaliadas de forma negativa. A identidade normal é "natural", desejável e única. A força da identidade normal é tal que ela nem sequer é vista como uma identidade, mas simplesmente como a identidade. Paradoxalmente, são as outras identidades que são marcadas como tais (SILVA, 2009, p. 83).
}

Movimento, Porto Alegre, v. 20, n. 4, p.1265-1282, out./dez. de 2014. 
Alvo de insultos, o sujeito queer ${ }^{18}$, aqui personalizado na figura de Fallon Fox, materializa uma vontade e também uma capacidade de inventar-se, de transformar-se, de colocar-se no mundo (LE BRETON, 2012). Como um artefato tecnológico, o corpo da lutadora resulta de distintos investimentos, tais como intervenções cirúrgicas, hormonais e estéticas, cujos resultados desafiam as normas regulatórias da sociedade e assumem o desconforto "da ambiguidade, do 'entre lugares', do indecidível” (LOURO, 2004, p. 7-8). As falas de Sandro Vilanova, Gustavo Rodrigues e Cezar Costa nomeiam esse desconforto:

Duvido, como e isso so por que tomou hormonios femininos perdeu toda a força, ou seja não atinje mais os picos de força de quando era homem, por quanto tempo?se parou como comprovar que ela não produz mais... (COMISSÃO..., 2013(sic)

Amigo, nao é tao somente a "testosterona que deixa o homem mais forte que a mulher". É o conjunto fisiológico, estrutural e anatômico... Se fosse só hormonios tava facil. Cada um faz suas escolhas, e vive com as consequencias delas. Dizer, por outro giro, que "homem vira mulher" e pronto, é simplesmente matar a ciência, a logica, a realidade... Em nome de fazer prevalecer o q se quer, ainda que irreal (LUTADORA..., 2013,(sic)

Nada a ver, a Ronda enfrentou a Camouche que é lesbica asumida porém é mulher, o problema desse daí é que ta na cara que é homem mesmo não adianta querer enganar. A comissão atletica deveria negar licença a qualquer lutador que esteja em tratamento hormonal, seja para repor ou suprimir, pois essas substancias são ilegais e anti-esportivas além de ser contra a natureza. (LUTADORA..., 2013(sic)

\footnotetext{
${ }^{18}$ Richard Miskolci (2012, p. 24) alerta que a palavra queer, em inglês, é um xingamento, um palavrão, uma injúria. Desponta com essa representação em função da epidemia da aids. Nesse contexto, a referência à Queer Nation era de que "parte da nação foi rejeitada, foi humilhada, considerada abjeta, motivo de desprezo e nojo, medo de contaminação. É assim que surge o queer, como reação e resistência a um novo momento biopolítico instaurado pela aids."
}

Movimento, Porto Alegre, v. 20, n. 4, p. 1265-1282, out./dez. de 2014. 
As manifestações que atestam a suposta vantagem física da Rainha de Espadas sobre suas oponentes indicam o quanto o uso de tecnologias corporais para a construção da feminilidade em corpos masculinos e da masculinidade em corpos femininos evoca e desacomoda o lugar de verdade do modelo binário dos sexos. A reengenharia do corpo queer e sua exibição no campo dos esportes de combate possibilitaram alargar horizontes sobre os limites do corpo, sua pluralidade e ambivalência. Permitiram ainda que observássemos o quanto o discurso biomédico é potente para distinguir e hierarquizar o normal e o patológico, de modo a normalizar indivíduos e populações. A abjeção ao corpo transexual adquire sentido quando analisamos a potência do saber médico que, segundo Foucault (2001), desde o século XVIII se ocupa de questões para além das enfermidades, chamando para si a "tarefa perpétua de restituir o sistema de normalidade". Não é sem razão que os argumentos trazidos pelos usuários instituem o corpo e a identidade de Fallon Fox como desviante, cuja verdade somente poderá ser dita ou anunciada pela medicina, por seus saberes e poderes.

\section{Transfobia E HOMOFOBIA: "DAQUI A POUCO VAMOS TER ESSAS ABERRAÇÕES QUERENDO JOGAR FUTEBOL FEMININO"19}

Os estudos queer propõem, a partir da teorização de Judith Butler (2010), que o sexo se faz existir nos processos de significação do binarismo macho/fêmea, matriz de inteligibilidade segundo a qual somente sobre os corpos femininos pode se dar a construção de mulheres, e vice-versa.

Quando o status construído do gênero é teorizado como radicalmente independente do sexo, o próprio gênero se torna um artifício flutuante, com a consequência de que homem e masculino podem, com igual facilidade, significar tanto um corpo feminino como um masculino, e mulher e feminino, tanto um corpo masculino como um feminino. (BUTLER, 2010, p. 24-25).

\footnotetext{
${ }^{19}$ Rodrigo Pires, em comentário no site Combate, no dia 8/4/2013.
}

Movimento, Porto Alegre, v. 20, n. 4, p.1265-1282, out./dez. de 2014. 
Essas múltiplas possibilidades indicam que o corpo, assim como as subjetividades, é singular. No caso da transexualidade, essa singularidade agrega outros significados, porque subverte a identidade de gênero representada como normal, ao mesmo tempo em que evidencia a inexistência da identidade primária.

O corpo abjeto de Fallon Fox no MMA provocou comentários que extrapolaram o universo das lutas e trouxeram à cena situações nas quais foi possível identificar fobia, aversão e repulsa aos sujeitos que subvertem as representações normatizadas de gênero e de sexualidade, aqui exemplificadas pelas postagens de Márcio Tokashiki, Mario Mendonça, Maicon Sousa, Fredson Lavra e Jader Rosa:

[...] totalmente contra nada haver que porra de bagunça sou totalmente contra homem que virou mulher competir com mulher tomara que leve um pau palhaço. (COMISSÃO..., 2013(sic)

A verdade é que esse país esta uma tremenda vergonha, e um tal de mulher se declarar para mulher homem dizendo que ama homem e tudo mais. Ok alguns dizem que isso é normal pois bem: digamos que um pai de família vai passear com sua família em um shopping no final de semana, e no meio do passeio suas filhas observam duas mulheres se beijando apaixonadamente ou até mesmo dois homens. Me respondam uma coisa o que irá passar na cabeça dessas crianças? Como um pai ou uma mãe irá explicar uma coisa nojenta dessa? Vai dizer que é normal? Brasil país da vergonha, Gays, ladrão e politico imperam!!! (APÓS..., 2013 (sic)

Que pena que o holocausto não conseguiu eliminar essa aberração da natureza na quela época, talvez hoje poderia ter bem menos desses lixos. (APÓS..., 2013(sic)

\section{ABERRAÇÃO DA NATUREZA... (TRANSEXUAL..., 2013(sic)}

Tá certo quem que expor a opinião mesmo, qual o problema? agora somos obrigados a engolir 
todo tipo de gay e lésbicas que aparecerem, sem questionar? isso é uma vergonha mesmo, se quiser mudar de sexo, mude, afinal o mundo tá virado mesmo, mas mudar e competir contra mulheres é muita palhaçada mesmo. Isso não vai ser mulher nunca na vida, como os Gays também nunca serão, jamais serão. (APÓS..., 2013(sic)

Dentro da lógica binária do par homem-mulher, as questões relacionadas à transexualidade e à homossexualidade provocam reações que patologizam tanto a lutadora quanto quem a defende. Bento e Pelúcio (2012, p. 571) contribuem para compreendermos por que motivo surge esse modo de abordar a questão:

As performances de gênero, a sexualidade e a subjetividade são níveis constitutivos da identidade do sujeito que se apresentam colados uns aos outros. O masculino e o feminino só se encontram por intermédio da complementaridade da heterossexualidade. Quando há qualquer nível de descolamento, deve haver uma intervenção especializada, principalmente de algum especialista nas ciências psi, para restabelecer a ordem e a "coerência" entre corpo, gênero e sexualidade. É esse mapa que fornecerá as bases fundamentais para a construção do diagnóstico de gênero.

No caso específico dos comentários postados nos sites analisados, a associação entre transexualidade e homossexualidade, além de recorrente, gerou reações contundentes. Vejamos as falas de Tiago Oliveira, Leonardo Oliveira, Gustavo Noberto e José Silva:

uai luta como homem.. eu iria bater tanto na cara ate ele vai querer virar homem de novo.. (LUTADORA..., 2013(sic)

Um homen contra uma mulher... porque que o Fallon Fox ñ luta com gente igual ele... vamos fazer assim se ELE vencer a proxima luta devia pegar o Demetrious Johnson (CURTINHAS..., 2013(sic)

Movimento, Porto Alegre, v. 20, n. 4, p.1265-1282, out./dez. de 2014. 
concerteza tem q parar com essas aberrações, ser gay ñ é normal, existe o macho e a fêmea pq afinal??? se fosse para todos serem gays, então pra 2 tipo de sexo?? e flando seriu se essa coisa for para o ufc vai luta no feminino ou no masculino? (APÓS..., 2013(sic)

Vão botar pra lutar com as mulheres, pra querer mostrar que é tudo normal, homem virar mulher e normal, depois lutar com mulher é normal, tudo aberração! Tomara que leve uma cossa igual aquela lésbica levou da ronda rousey na ultima luta. (APÓS..., 2013(sic)

O esporte, assim como outras práticas sociais, é um local de disputa de saberes e poderes que definem e delimitam padrões de normalidade sobre a aparência dos corpos, o exercício da sexualidade e a experimentação das representações de gênero. As pessoas que postaram os comentários designaram como abjeto tanto o corpo de Fallon quanto a atleta como sujeito. A abjeção, segundo Butler (2003, p. 162) está intimamente relacionada ao fato de não pertencer a lugar nenhum, o que implica a negação da possibilidade de ser, pois, quando o sujeito não se encaixa em nenhum gênero da ordem binária, ele fica "fora do humano, constituem a rigor o domínio desumanizado e do abjeto, em contraposição ao qual o próprio humano se estabelece".

A não aceitação daquilo que identificam como identidades desviantes evidencia a potência em perpetuar e manter o que Adrienne Rich (1980) chamou de "heterossexualidade compulsória - a ordem dominante pela qual os homens e as mulheres se veem solicitados ou forçados a ser heterossexuais" (SALIH, 2012, p. 71). Fallon Fox, assim como outros sujeitos "da sexualidade desviante homossexuais, bissexuais, transexuais, travestis, drags" (LOURO, 2004, p. 7-8), subverteu essa ordem, ultrapassando fronteiras rígidas que, demarcadas pelo discurso biomédico, inscrevem nos sujeitos a marca da normalidade. Os insultos que apareceram nas 
mensagens postadas pelos usuários evidenciaram que a homofobia e a transfobia são facilmente referidas em situações nas quais a linearidade corpo, gênero, sexo e desejo é desconstruída, seja no campo do esporte, seja fora dele.

\section{ConsideraçõEs finaIS}

A inserção de uma lutadora transexual em um esporte no qual proliferam atributos ligados a uma dada representação de masculinidade pode ser lida de diversos modos e com diferentes intenções. Optamos por ressaltar o caráter pedagógico e político dessa presença, seja porque visibilizou a pluralidade dos corpos, dos gêneros e das sexualidades, seja porque, ao optar por praticar um esporte de combate, Fallon Fox, um homem modificado em mulher, novamente rompeu com o que supostamente poderia ser esperado: ao feminizar-se não buscou práticas corporais culturalmente mais indicadas para seu sexo ressignificado. Ao contrário: se inseriu em uma prática corporal que exige disciplina, dedicação e investimento, cujos efeitos produzem um corpo forte e ágil, capaz de suportar muitos golpes e pancadas. Um corpo culturalmente significado como viril, o qual, no seu caso, foi apagado e reconstruído com outros atributos e significados. Um corpo queer: indecifrável, excêntrico e ambíguo. Um corpo que, ao ser exibido no octógono, traz para o esporte novos horizontes e possibilidades.

Movimento, Porto Alegre, v. 20, n. 4, p.1265-1282, out./dez. de 2014. 
Fallon Fox: a queer body in the octagon
Abstract: Based in gender studies and queer theory, this paper
analyzes the inclusion of Fallon Fox as a professional athlete at
Mixed Martial Arts, more specifically, her fight against Allanna
Jones in the semifinals of the Championship Fighting Alliance. It
examines 510 comments posted on three specific cultural artifacts
related to fighting sports, seeking to understand the discourses that
its users produced about the participation of a transgender athlete.
From the analysis of empirical data, we found that the arguments
used to justify the improper nature of the contest were based in
two perspectives: the use of legal and medical discourses to attest
the advantage of Fallon Fox over her opponent and transphobia,
understood as aversion or repulsion to trans people.
Keywords: Mixed Martial Arts. Transgender. Athletes.

Fallon fox: un cuerpo queer en el octógono.

Resumen: Fundamentado en los estudios de género y en la teorización queer, este texto analiza la inserción de Fallon Fox como atleta profesional del Mixed Martial Arts, más específicamente la lucha contra Allanna Jones en las semifinales Championship Fighting Alliance. Por lo tanto, analiza 510 comentarios publicados en tres artefactos culturales específicos de luchas, buscando aprehender los discursos que sus usuarios produjeron sobre la participación de una atleta transgénero. Del análisis de los datos empíricos, fue posible identificar que los argumentos utilizados para justificar el carácter impropio de la disputa estaban establecidos en dos perspectivas: la utilización de discursos jurídicos y médicos para certificar la ventaja de Fallon Fox sobre su oponente y la transfobia, entendida como la aversión o repulsión a las personas trans.

Palabras clave: Artes Marciales Mixtas. Transgénero. Atletas.

\section{Referências}

APÓS críticas à lutadora transexual, Matt Mitrione é suspenso do UFC. Combate, Rio de Janeiro, 8 abr. 2013. Disponível em: <http://sportv.globo.com/site/combate/noticia/2013/04/ apos-criticas-fallon-fox-lutador-matt-mitrione-e-suspenso-do-ufc.html>. Acesso em: 9 abr. 2013.

BADIN, Laurence. Análise de conteúdo. São Paulo: Edições 70, 2011.

BENTO, Berenice; PELÚCIO; Larissa. Despatologização do gênero: a politização das identidades abjetas. Estudos Feministas, Florianópolis, v. 20, n. 2, p. 569-581, maio/ago. 2012.

BUTLER, Judith. Problemas de gênero: feminismo e subversão da identidade. Rio de Janeiro: Civilização Brasileira, 2010.

Movimento, Porto Alegre, v. 20, n. 4, p. 1265-1282, out./dez. de 2014. 
COMISSÃO libera e atleta transexual enfrentará mulher em evento de MMA. Tatame, Rio de Janeiro, 4 abr. 2013. Disponível em: <http://www.tatame.com. $\mathrm{br} /$ comissao-libera-e-atleta-transexual-enfrentaria-mulher-em-evento-de-mma>. Acesso em: 5 abr. 2013.

CORREAA, Jorge. UFC no FOX 8 terá cinturão dos moscas, duas lutas femininas e pesado que ofendeu transexual. Na Grade do MMA, 25 abr. 2013. Disponível em: $\quad<$ http://nagradedomma.blogosfera.uol.com.br/2013/04/25/ufc-on-fox-8-teracinturao-dos-moscas-duas-lutas-femininas-e-pesado-que-ofendeu-transexual $\geq$. Acesso em: 26 abr. 2013.

CURTINHAS: Adversária aceita luta com transexual, mas comissão ainda avalia. Combate, Rio de Janeiro. 2 abr. 2013. Disponível em: <http://sportv.globo.com/ site/combate/noticia/2013/04/curtinhas-adversaria-aceita-luta-com-transexualmas-comissao-ainda-avalia.html>. Acesso em: 3 abr. 2013.

DEHÓ, Maurício. UFC: 65 lutas e 128 nocautes em 2013. Na Grade do MMA, 5 jan. 2014. Disponível em: <http://nagradedomma.blogosfera.uol.com.br/2014/01/05/ ufc-65h-de-lutas-e-128-nocautes-em-2013>. Acesso em: 6 jan. 2014.

FERRETTI, Marco Antonio de Carvalho; KNIJNIK, Jorge Dorfman. Mulheres podem praticar lutas? Um estudo sobre as representações sociais de lutadoras universitárias. Movimento, Porto Alegre, v. 13, n. 1, p. 57-80, jan./abr. 2007.

FOUCAULT, Michel. A ordem do discurso. São Paulo: Edições Loyola, 1996.

FOUCAULT, Michel. Ditos e escritos III. Estética: Literatura e Pintura, Música. Rio de Janeiro: Forense Universitária, 2001.

HUNT, Loretta. How Fallon Fox became the first known transgender athlete in MMA. 2013. Disponível em: <http://sportsillustrated.cnn.com/mma/news/20130307/ fallon-fox-profile>. Acesso em: 15 jun. 2013.

LAQUEUR, Thomas. Inventando o sexo: corpo e gênero dos gregos a Freud. Rio de Janeiro: Relume, 2001.

LE BRETON, David. Individualização do corpo e tecnologias contemporâneas. In: COUTO, Edvaldo Souza; GOELLNER, Silvana Vilodre (Org.). O triunfo do corpo: polêmicas contemporâneas. Petrópolis: Vozes, 2012.

LOURO, Guacira Lopes. Um corpo estranho: ensaios sobre a sexualidade e a Teoria Queer. Belo Horizonte: Autêntica Editora, 2004.

LUTADORA transexual considera injusto ter de revelar seu histórico médico. Combate, Rio de Janeiro,19 mar. 2013. Disponível em: <http://sportv.globo.com/ site/combate/noticia/2013/03/lutadora-transexual-considera-injusto-ter-de-revelarseu-historico-medico.html>. Acesso em: 20 mar. 2013.

MELONI, Carolina. Judith Butler y la genealogía. La Torre del Virrey: Revista de Estudios Culturales, Valencia, (Espanha), n. 5, p. 75-81, 2008. Disponível em: <http://www. latorredelvirrey.es/pdf/05/carolina.meloni.pdf>. Acesso em 3 maio 2012.

Movimento, Porto Alegre, v. 20, n. 4, p.1265-1282, out./dez. de 2014. 
MISKOLCI, Richard. Teoria Queer: um aprendizado pelas diferenças. Belo Horizonte: Autêntica, 2012.

MITRIONE ataca lutadora transexual: 'Doente, sociopata e nojenta'. Combate, Rio de Janeiro, 8 abr. 2013. Disponível em: <http://sportv.globo.com/site/combate/ noticia/2013/04/mitrione-ataca-lutadora-transsexual-doente-sociopata-e-nojenta. html>. Acesso em: 9 abr. 2013.

NEPOMUCENO, Margarete Almeida. O colorido do cinema Queer: onde o desejo subverte imagens. In: II SEMINÁRIO NACIONAL GÊNERO E PRÁTICAS CULTURAIS. João Pessoa: UFPB, 2009. p. 01- 12. Disponível em: < http:// itaporanga.net/genero/gt6/13.pdf > . Acesso em: 17 out. 2010.

REVEL, Judith. Dicionário de Foucault. Rio de Janeiro: Forense Universitária, 2011.

$\mathrm{RICH}$, Adrienne. Compulsory Heterosexuality and Lesbian Existence. Signs: Journal of Women in Culture and Society, Chicago, v. 5, n. 4, p. 631-660, Summer 1980.

RONDA Rousey é contra entrada de atletas transexuais no MMA feminino. Tatame, 15 abr. 2013. Disponível em: <http://www.tatame.com.br/ronda-rousey-e-contra-aparticipacao-de-transexuais-no-mma-feminino >. Acesso em: 16 abr. 2013.

SALIH, Sara. Judith Butler e a Teoria Queer. Belo Horizonte: Autêntica Editora, 2012.

SILVA, Tomaz Tadeu da. A produção social da identidade e da diferença. In: . Identidade e diferença: a perspectiva dos Estudos Culturais. Petrópolis:

Vozes, 2009. p. 73-102.

SILVESTRIN, Julia Mara Pegoraro. Perform(atividade) na escola: reflexões sobre gênero na Educação Física. Dissertação (Mestrado em Educação Física) Universidade Federal de Santa Catarina, Florianópolis, 2013.

TRANSEXUAL enfrenta problemas para obter licença e lutar no MMA feminino. Combate. cidade, 6 mar. 2013, Disponível em: <http://sportv.globo.com/site/ combate/noticia/2013/03/transexual-enfrenta-problemas-para-obter-licenca-elutar-no-mma-feminino.html>. Acesso em: 7 mar. 2013.

Endereço para correspondência:

Rua Dona Margarida $\mathrm{n}^{\circ} 144$

Bairro Navegantes

Porto Alegre/ RS

CEP: $90.240-610$

Recebido em: 03.04.2014

Aprovado em: 14.06.2014

Movimento, Porto Alegre, v. 20, n. 4, p. 1265-1282, out./dez. de 2014. 